\title{
Regulation of Caenorhabditis elegans RNA Interference by the daf-2 Insulin Stress and Longevity Signaling Pathway
}

\author{
D. WANG AND G. RUVKUN \\ Department of Molecular Biology, Massachusetts General Hospital and Department of Genetics, \\ Harvard Medical School, Boston, Massachusetts 02114
}

\begin{abstract}
A conserved insulin-like signaling pathway regulates metabolism, development, stress resistance, and life span in Caenorhabditis elegans (Lee et al. 2003). This pathway involves an insulin-like receptor DAF-2, a phosphatidylinositol-3-OH kinase (PI3K) AGE-1, and the kinases AKT-1, AKT-2 (Paradis and Ruvkun 1998), and PDK-1 (Paradis et al. 1999), as well as the fork head transcription factor DAF-16 (Ogg et al. 1997; Lee et al. 2003). Loss-of-function mutations in daf-2 or age-1 cause the worm to arrest at the dauer diapause stage rather than proceeding to reproductive development (Ogg et al. 1997). In addition, the daf-2 and age-1 mutants have increased life span and stress resistance, compared with wild type (Ogg et al. 1997; Honda and Honda 2002; Lee et al. 2003). Both the dauer-constitutive and life span phenotypes of the daf-2 or age-1 mutants are suppressed by loss-of-function mutation in the downstream daf-16 gene (Ogg et al. 1997).
\end{abstract}

RNA interference, or RNAi, is well conserved across phylogeny and protects the genome from invasive genetic elements such as transposons and viruses (Denli and Hannon 2003). Exogenous double-stranded RNA (dsRNA) is cleaved by the RNase III Dicer into 22-nucleotide short interfering RNA (siRNA) (Bernstein et al. 2001). siRNA is incorporated into a protein complex called RNA-induced silencing complex (RISC), which recognizes and destroys the target mRNA based on the sequence homology between the target mRNA and the trigger dsRNA (Song et al. 2004).

Here we show that $C$. elegans mutants with decreased insulin-like signaling have a more intense RNAi response than wild type. Such regulation of RNAi by this stress and longevity signaling pathway suggests a role in response to pathogens such as viruses.

\section{SECTION THEMES}

\section{Decreased age-1/PI3-Kinase Signaling Enhances RNAi}

Mutants lacking age-1 activity show enhanced response to RNAi. We used dsRNAs, which cause less severe or penetrant phenotypes than the corresponding loss-of-function mutations, to test the insulin signaling-defective mutants. age-1(mg305) is a temperaturesensitive allele that causes dauer arrest at $25^{\circ} \mathrm{C}$ or higher temperatures. age-1 (mg305) animals display a tempera- ture-sensitive enhanced RNAi response at the nonpermissive temperature of $25^{\circ} \mathrm{C}$. For instance, loss-of-function mutation in the $l i n-1$ ETS transcription factor gene causes production of multiple vulvae (Muv). RNAi of lin- 1 causes multiple vulvae in $96 \%$ of the age-1( $\mathrm{mg} 305)$ mutants at $25^{\circ} \mathrm{C}$, but $0 \%$ at $20^{\circ} \mathrm{C}$, and $0 \%$ of wild-type animals at both temperatures. Similarly, mutations in the daf-2/insulin-like receptor gene show enhanced response to RNAi (Table 1). The increase in longevity, stress resistance, and fat storage caused by daf-2 or age- 1 mutations is strongly suppressed by mutations in daf-16, a fork head transcription factor coding gene. The enhanced RNAi phenotype is also mediated by signaling via DAF16: the age-1;daf-16 double mutant shows wild-type response to lin-1 dsRNA (Table 2). These data suggest that insulin-like signaling normally inhibits RNAi via the DAF-16 transcriptional cascade.

\section{age-1 Mediates RNAi Response via mRNA Abundance}

The phenotypic difference between age-1 and wild type in response to dsRNA correlates with the different change of the target mRNA level. RNAi of the histone gene his-44 gene causes $100 \%$ early larval arrest in age1 (mg305), but does not cause this phenotype in wild type. Similarly, other RNAi of a wide range of histone genes is enhanced in age-1(mg305). Consistent with the enhanced RNAi phenotype, northern analysis shows that after feeding his-44 dsRNA, his-44 mRNA level is significantly decreased in age-1(mg305), whereas no change is observed in wild type (Fig. 1). This decrease in his-44 mRNA level was similar to that induced by the previously known RNAi enhancer mutant rrf-3(pk1426) (Simmer et al. 2002), which also enhances the lethality induced by his-44 RNAi. Therefore, the insulin-like pathway enhances RNAi by facilitating the degradation of target mRNA.

\section{The Dauer-Regulatory Pathways Overlap with the RNAi Pathway}

Three parallel signaling cascades regulate dauer arrest in $C$. elegans: the daf-2/insulin-like, daf-7/TGF- $\beta$-like, and $d a f-11 /$ cyclic GMP pathways (Li et al. 2003). Mutants lacking activity of either pathway arrest at the dauer stage; however, only mutations in the daf-2 insulin-like pathway 
Table 1. The Dauer-Constitutive Mutants Show Different Sensitivity to RNAi

\begin{tabular}{lcccc}
\hline & \multicolumn{4}{c}{$\begin{array}{c}\text { Feeding RNAi } \\
\text { (phenotype) }\end{array}$} \\
\cline { 2 - 5 } Strains & his-44 & $\begin{array}{c}\text { lin-1 } \\
\text { (\% Muv) }\end{array}$ & $\begin{array}{c}\text { hmr-1 } \\
\text { (\% embryonic lethal) }\end{array}$ & $\begin{array}{c}\text { col-183 } \\
\text { (dumpy) }\end{array}$ \\
\hline age-1(mg305ts $)$ & $75 \pm 2$ & $96 \pm 7$ & $81 \pm 8$ & + \\
daf-2(e1370ts) & $91 \pm 6$ & $65 \pm 6$ & $79 \pm 5$ & + \\
daf-7(mg1372ts) & $7 \pm 3$ & $22 \pm 5$ & $41 \pm 9$ & - \\
daf-11(mg295ts) & $9 \pm 6$ & $0 \pm 0$ & $35 \pm 7$ & - \\
rrf-3(pk1426) & $86 \pm 11$ & $77 \pm 10$ & $96 \pm 2$ & ++ \\
Wild type (N2) & $12 \pm 9$ & $0 \pm 0$ & $28 \pm 6$ & - \\
\hline
\end{tabular}

Animals were fed bacteria expressing dsRNA targeting his-44, lin-1, or col-183 from the L1 stage at $25^{\circ} \mathrm{C}$. For the lin-1 and col-183 experiment, dauers from $25^{\circ} \mathrm{C}$ were recovered at $20^{\circ} \mathrm{C}$ and allowed to proceed to adulthood when the multiple vulval (Muv) and dumpy body shape phenotypes were scored. For the col-183 experiment,,-+ , and ++ indicate no (-), dumpy (+), and extremely dumpy (++) body shape. For the $h m r-1$ experiment, animals at young adult stage were fed $h m r-1$ dsRNA and the percentage of embryonic lethality among their progeny was scored.

increase longevity and stress resistance of reproductively growing animals (Tissenbaum and Ruvkun 1998; Wolkow et al. 2000). To decide whether the RNAi-enhanced phenotype is caused by some general dauer-inducing signal shared by all three pathways, we tested the RNAi response of dauer-constitutive mutants in the other two pathways, daf-7/TGF- $\beta$ and daf-11/guanylate $c y$ clase. daf-11(mg295ts) is no more sensitive to RNAi than wild type. daf-7(mg1372) is slightly more sensitive than wild type to $\mathrm{lin}-1$ ( $22 \%$ Muv vs. $0 \%$ in wild type) and $\mathrm{hmr}$ 1 (41\% embryonic lethal vs. $28 \%$ in wild type) dsRNAs, but no different than wild type in response to his-44 dsRNA ( $7 \%$ embryonic lethal vs. $12 \%$ in wild type) or $\mathrm{col}$ 183 dsRNA (not dumpy) (Table 1). The weak RNAi enhancement of a daf-7 mutant may reflect the known crosstalk between the insulin and TGF- $\beta$ pathways (Lee et al. 2001; Li et al. 2003). We conclude that RNAi, like stress resistance and longevity, is most affected by mutations in the insulin-like pathway.

\section{CONCLUSIONS}

Mutations in the insulin-like pathway enhance RNAi response and this enhancement is dependent on the DAF16 fork head transcription factor. The insulin-like metabolic and longevity signaling is transduced by the fork head transcription factor DAF-16 (Ogg et al. 1997).

Table 2. The age-1 Mutant Has Enhanced Response to lin-1 dsRNA

\begin{tabular}{lrr}
\hline & \multicolumn{2}{c}{$\%$ of Muv animals } \\
\cline { 2 - 3 } Strains & $20^{\circ} \mathrm{C}$ & $25^{\circ} \mathrm{C}$ \\
\hline age-1(mg305ts $)$ & $0 \pm 0$ & $96 \pm 7$ \\
daf-16(mgDf47) & $1 \pm 3$ & $5 \pm 5$ \\
age-1(mg305ts); daf-16(mgDf47) & $1 \pm 2$ & $7 \pm 3$ \\
rrf-3(pk1426) & $64 \pm 6$ & $77 \pm 4$ \\
Wild type (N2) & $0 \pm 0$ & $0 \pm 0$ \\
\hline
\end{tabular}

Animals of the indicated genotypes were fed bacteria expressing lin- $1 \mathrm{dsRNA}$ at $20^{\circ} \mathrm{C}$ or $25^{\circ} \mathrm{C}$ since the L1 larval stage. The percentage of animals with multiple vulval structures (Muv) was scored. For the experiment with age-1(mg305) at $25^{\circ} \mathrm{C}$, animals arrested as dauers and were then recovered at $20^{\circ} \mathrm{C}$ to proceed to adulthood when the Muv phenotype was scored.
The nuclear localization of DAF-16 is regulated by insulin-like signaling (Lee et al. 2001). One model for how insulin-like signaling affects RNAi is that components that positively regulate RNAi, like $d c r-1$ and $r d e-1$, are positively regulated by DAF-16; or components that negatively regulate RNAi, like eri-1 (Kennedy et al. 2004) and $r r f-3$ (Simmer et al. 2002), are negatively regulated by DAF-16. The DAF-16 binding site has been determined and 947 C. elegans genes were identified to bear at least one DAF-16 binding site within 1 kilobase $(\mathrm{kb})$ upstream of their predicted transcriptional start sites. Among these genes, 17 genes are orthologous between Drosophila and C. elegans, highlighting the response pathways that may be conserved (Lee et al. 2003). None of those conserved genes with consensus DAF-16 binding sites correspond to known RNAi factors, but many regulatory steps in RNAi have yet to be identified.

Recent study shows that a conserved and pancreatic islet-specific microRNA, miR375, regulates the insulin signaling pathway in mammals (Poy et al. 2004). Overexpression of miR375 suppresses glucose-induced insulin secretion and, conversely, inhibition of endogenous miR-375 function enhances insulin secretion (Poy et al. 2004). MicroRNA processing shares the same machinery with RNAi, which includes the RNase III Dicer and the Argonaute proteins ALG-1 and ALG-2 (Grishok et al. 2001). The fact that mutation in the insulin-like pathway enhances RNAi suggests a possible negative feedback between insulin signaling and miRNA/siRNA process-

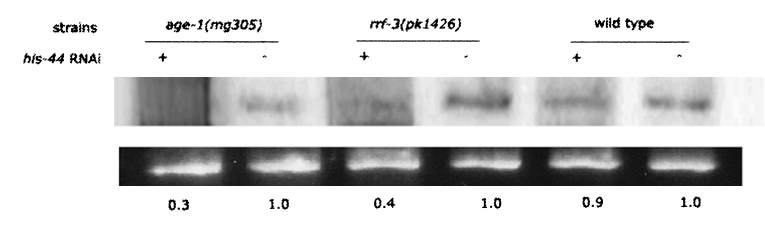

Figure 1. Mutation in age- 1 enhances the suppression of the target mRNA of RNAi. age-1(mg305), rrf-3(pk1426), and wild type were fed bacteria expressing his-44 dsRNA (+) or a control vector L4440 (-) for $12 \mathrm{hr}$ at $25^{\circ} \mathrm{C}$. The change of mRNA was determined by northern blot. 
ing. Such a feedback loop could control the amount of insulin signaling via regulation of microRNAs that in turn regulate the secretion of insulins.

Alternatively, the interaction between the insulin and RNAi pathways may occur at the chromatin level. In C. elegans, dauer larvae express histone $\mathrm{H} 1$ at a higher level than nondauer animals (Jones et al. 2001). The C. elegans homolog of SIR-2, which mediates chromatin silencing in yeast, functions in the insulin-like signaling pathway. Overexpression of the sir-2 gene mimics the loss-of-function mutation in daf-2 or age- 1 to extend the life span and favors the dauer entry, and both phenotypes are suppressed by a mutation in the downstream daf- 16 gene (Tissenbaum and Guarente 2001). A distinct chromatin packaging in dauers and animals deficient in insulin signaling may enhance the action of siRNAs in chromatin remodeling to suppress the transcription of RNAi target genes. On the other hand, components of the RNAi machinery, including Dicer and Argonaute, are required for the assembly and localization of heterochromatin in flies (Pal-Bhadra et al. 2004) and fission yeast (Verdel et al. 2004). There may be a competition between heterochromatin formation and RNAi. It is possible that the change in chromatin structure in the daf-2 mutants releases RNAi components from heterochromatin to now allow a more robust silencing of mRNAs.

Mutants lacking the insulin-like signaling, such as daf2 and age- 1 , are more resistant than wild type to environmental stresses (Honda and Honda 2002) as well as pathogens (Garsin et al. 2003). RNAi components also mediate silencing of transposons in C. elegans (Sijen and Plasterk 2003) as well as resistance to virus infection in Arabidopsis (Mourrain et al. 2000). Thus the coupling of RNAi responses to the stress resistance pathway of daf2/insulin-like signaling makes biological sense - as part of a stress resistance pathway, RNAi responses may be enhanced. It is intriguing to contemplate that the aging regulation by the daf-2/insulin signaling pathway could also depend in part on RNAi pathways.

\section{ACKNOWLEDGMENTS}

We thank W. Li, S. Kennedy, C. Wolkow, H.A. Tissenbaum, A. Hart, and J. Kaplan for insightful discussion.

\section{REFERENCES}

Bernstein E., Caudy A.A., Hammond S.M., and Hannon G.J. 2001. Role for a bidentate ribonuclease in the initiation step of RNA interference. Nature 409: 363.

Denli A.M. and Hannon G.J. 2003. RNAi: An ever-growing puzzle. Trends Biochem. Sci. 28: 196.

Garsin D.A., Villanueva J.M., Begun J., Kim D.H., Sifri C.D., Calderwood S.B., Ruvkun G., and Ausubel F.M. 2003. Longlived $C$. elegans daf-2 mutants are resistant to bacterial pathogens. Science 300: 1921.

Grishok A., Pasquinelli A.E., Conte D., Li N., Parrish S., Ha I., Baillie D.L., Fire A., Ruvkun G., and Mello C.C. 2001. Genes and mechanisms related to RNA interference regulate expres- sion of the small temporal RNAs that control C. elegans developmental timing. Cell 106: 23.

Honda Y. and Honda S. 2002. Oxidative stress and life span determination in the nematode Caenorhabditis elegans. Ann. N.Y. Acad. Sci. 959: 466.

Jones S.J., Riddle D.L., Pouzyrev A.T., Velculescu V.E., Hillier L., Eddy S.R., Stricklin S.L., Baillie D.L., Waterston R., and Marra M.A. 2001. Changes in gene expression associated with developmental arrest and longevity in Caenorhabditis elegans. Genome Res. 11: 1346.

Kennedy S., Wang D., and Ruvkun G. 2004. A conserved siRNA-degrading RNase negatively regulates RNA interference in C. elegans. Nature 427: 645.

Lee R.Y., Hench J., and Ruvkun G. 2001. Regulation of C. elegans DAF-16 and its human ortholog FKHRL1 by the daf-2 insulin-like signaling pathway. Curr. Biol. 11: 1950.

Lee S.S., Kennedy S., Tolonen A.C., and Ruvkun G. 2003. DAF-16 target genes that control C. elegans life-span and metabolism. Science 300: 644.

Li W., Kennedy S.G., and Ruvkun G. 2003. daf-28 encodes a $C$. elegans insulin superfamily member that is regulated by environmental cues and acts in the DAF-2 signaling pathway. Genes Dev. 17: 844.

Mourrain P., Beclin C., Elmayan T., Feuerbach F., Godon C., Morel J.B., Jouette D., Lacombe A.M., Nikic S., Picault N., Remoue K., Sanial M., Vo T.A., and Vaucheret H. 2000. Arabidopsis SGS2 and SGS3 genes are required for posttranscriptional gene silencing and natural virus resistance. Cell 101: 533 .

Ogg S., Paradis S., Gottlieb S., Patterson G.I., Lee L., Tissenbaum H.A., and Ruvkun G. 1997. The Fork head transcription factor DAF-16 transduces insulin-like metabolic and longevity signals in C. elegans. Nature 389: 994.

Pal-Bhadra M., Leibovitch B.A., Gandhi S.G., Rao M., Bhadra U., Birchler J.A., and Elgin S.C. 2004. Heterochromatic silencing and HP1 localization in Drosophila are dependent on the RNAi machinery. Science 303: 669.

Paradis S. and Ruvkun G. 1998. Caenorhabditis elegans Akt/PKB transduces insulin receptor-like signals from AGE1 PI3 kinase to the DAF-16 transcription factor. Genes Dev. 12: 2488 .

Paradis S., Ailion M., Toker A., Thomas J.H., and Ruvkun G. 1999. A PDK1 homolog is necessary and sufficient to transduce AGE-1 PI3 kinase signals that regulate diapause in Caenorhabditis elegans. Genes Dev. 13: 1438.

Poy M.N., Eliasson L., Krutzfeldt J., Kuwajima S., Ma X., Macdonald P.E., Pfeffer S., Tuschl T., Rajewsky N., Rorsman P., and Stoffel M. 2004. A pancreatic islet-specific microRNA regulates insulin secretion. Nature 432: 226.

Sijen T. and Plasterk R.H. 2003. Transposon silencing in the Caenorhabditis elegans germ line by natural RNAi. Nature 426: 310.

Simmer F., Tijsterman M., Parrish S., Koushika S.P., Nonet M.L., Fire A., Ahringer J., and Plasterk R.H. 2002. Loss of the putative RNA-directed RNA polymerase RRF-3 makes C. elegans hypersensitive to RNAi. Curr. Biol. 12: 1317.

Song J.J., Smith S.K., Hannon G.J., and Joshua-Tor L. 2004. Crystal structure of Argonaute and its implications for RISC slicer activity. Science 305: 1434.

Tissenbaum H.A. and Guarente L. 2001. Increased dosage of a sir-2 gene extends lifespan in Caenorhabditis elegans. Nature 410: 227.

Tissenbaum H.A. and Ruvkun G. 1998. An insulin-like signaling pathway affects both longevity and reproduction in Caenorhabditis elegans. Genetics 148: 703.

Verdel A., Jia S., Gerber S., Sugiyama T., Gygi S., Grewal S.I., and Moazed D. 2004. RNAi-mediated targeting of heterochromatin by the RITS complex. Science 303: 672 .

Wolkow C.A., Kimura K.D., Lee M.S., and Ruvkun G. 2000. Regulation of C. elegans life-span by insulinlike signaling in the nervous system. Science 290: 147. 


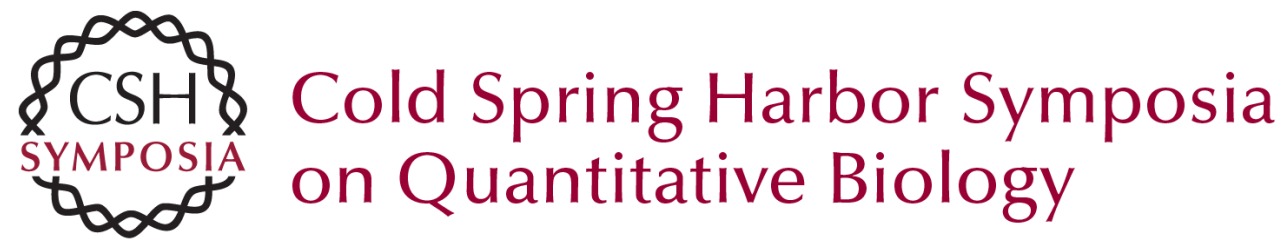

\section{Regulation of Caenorhabditis elegans RNA Interference by the daf-2 Insulin Stress and Longevity Signaling Pathway}

D. WANG and G. RUVKUN

Cold Spring Harb Symp Quant Biol 2004 69: 429-432

Access the most recent version at doi:10.1101/sqb.2004.69.429

References This article cites 23 articles, 11 of which can be accessed free at: http://symposium.cshlp.org/content/69/429.full.html\#ref-list-1

\section{License}

Email Alerting

Receive free email alerts when new articles cite this article - sign up in Service the box at the top right corner of the article or click here. 